\title{
Time-dependent effects on dynamic properties of cable-stayed bridges
}

\author{
Francis T.K. Au* and X.T. Si \\ Department of Civil Engineering, The University of Hong Kong, Pokfulam Road, Hong Kong, China
}

(Received May 11, 2011, Revised September 17, 2011, Accepted December 13, 2011)

\begin{abstract}
Structural health monitoring systems are often installed on bridges to provide assessments of the need for structural maintenance and repair. Damage or deterioration may be detected by observation of changes in bridge characteristics evaluated from measured structural responses. However, construction materials such as concrete and steel cables exhibit certain time-dependent behaviour, which also results in changes in structural characteristics. If these are not accounted for properly, false alarms may arise. This paper proposes a systematic and efficient method to study the time-dependent effects on the dynamic properties of cable-stayed bridges. After establishing the finite element model of a cable-stayed bridge taking into account geometric nonlinearities and time-dependent behaviour, long-term time-dependent analysis is carried out by time integration. Then the dynamic properties of the bridge after a certain period can be obtained. The effects of time-dependent behaviour of construction materials on the dynamic properties of typical cable-stayed bridges are investigated in detail.
\end{abstract}

Keywords: cable-stayed bridges; concrete creep; geometric nonlinearities; structural health monitoring systems; time-dependent behaviour

\section{Introduction}

Bridges are important links in almost every transportation system. As they may be damaged during their service lives due to service loads, and environmental and accidental actions, it is desirable to conduct regular condition assessment of important bridges to obtain information on the occurrence, geometric location and severity of any structural damage at the earliest possible stage to prevent these structures from any potential catastrophic events (Liu et al. 2009, Kim et al. 2011). Among various major crossings built over the past four decades, cable-stayed bridges have become very popular not only because of their remarkable structural efficiency but also their aesthetically pleasing appearance. With advances in material technology and the increasing use of high-strength materials together with slender structural members, the time-dependent behaviour associated with the higher stress levels has become an increasing concern.

In parallel with the gradual but steady increase in span lengths in cable-stayed bridges in recent decades, structural health monitoring (SHM) systems are increasingly installed on such bridges to monitor their performance and safety by observation of any changes in bridge characteristics caused

*Corresponding author, Professor, E-mail: francis.au@hku.hk 
by damage (Doebling et al. 1996, Zhang et al. 2008, Kim et al. 2011). However there are various components in cable-stayed bridges with time-dependent behaviour. For example, concrete structural members exhibit various time-dependent phenomena, including ageing which manifests as increase in elastic modulus (Cluley and Shepherd 1996), creep in the form of gradual increase of inelastic strain under sustained stress, and drying shrinkage in the form of shortening as a result of loss of moisture. Stay cables and prestressing tendons may experience stress relaxation or creep behaviour with time (Kmet et al. 2011). These time-dependent phenomena will affect the internal force distribution in the structure and its long-term performance, which also result in changes in bridge characteristics. If these issues are not considered properly, false positive or false negative alarm of SHM systems may arise. Therefore it is necessary to take such effects into account carefully in order to build a reliable monitoring system.

The use of finite element method in conjunction with time integration serves as a reliable tool for time-dependent analysis of concrete structure (Ghali et al. 2002, Au et al. 2009). In this method, the structural concrete components are usually represented as beam-column elements while the steel tendons embedded in concrete are modelled as truss elements with nodes connected to the beam nodes by rigid arms (Aalami 1998, Elbadry and Ghali 2001, Au et al. 2009). In order to account for the interaction among concrete creep, concrete shrinkage and cable relaxation accurately, the equivalent creep model for tendons proposed by Au and Si (2009) is used together with the creep and shrinkage models of concrete. The long-term performance of concrete structures can then be predicted accurately taking into account the time-dependent behaviour of concrete and steel tendons.

Although much work has been done on the time-dependent static behaviour of concrete structures, the effects of time-dependent behaviour on the dynamic performance of concrete structures have received relatively little attention. One of the first publications in this area was the investigation of creep and shrinkage effects of concrete on dynamic behaviour of reinforced concrete slab-and-beam structures (Sapountzakis and Katsikadelis 2003). Ma et al. (2011) studied the creep effects on dynamic behaviour of concrete-filled steel tube arch bridge. Both of their results showed that the natural frequencies would decrease gradually with time as some kind of long-term effective modulus (Trost and Wolff 1970, Bažant 1972) was adopted. As there has been little work in this respect done on cable-stayed bridges, it is necessary to develop a systematic and reliable method to investigate the effect of time-dependent behaviour due to concrete ageing, creep and shrinkage, and cable relaxation on the dynamic properties of such structures. It not only improves our understanding of the long-term performance of this kind of bridges of emerging importance, but it also ensures that any such SHM system can be made reliable in the long run. However it should be pointed out that the present analysis does not take into consideration the effects of damage, deterioration due to corrosion, etc. as they are based on totally different mechanisms.

\section{Methodology for analysis of time-dependent behaviour}

\subsection{Equivalent creep coefficient for steel tendons}

The intrinsic stress relaxation $\Delta \sigma_{p r}$ in a steel cable is the loss of stress at constant strain. It depends on both the duration of sustained tension $t$ (hours) and the ratio of the initial prestress $\sigma_{p i}$ to the "yield" strength of steel $f_{p y}$. The equation commonly adopted for the stress-relieved strands or wires (Magura et al. 1964) for $\sigma_{p i} / f_{p y} \geq 0.55$ is 


$$
\frac{\Delta \sigma_{p r}(t)}{\sigma_{p i}}=-\frac{\log (t)}{10}\left(\frac{\sigma_{p i}}{f_{p y}}-0.55\right)
$$

In the derivation of equivalent creep coefficient for steel tendons, it is assumed that the creep coefficient is independent of age and the modulus of elasticity $E_{s}$ remains constant. Given the type of tendon and based on the intrinsic stress relaxation, the creep coefficient $\bar{\varphi}_{s}(t)$ of a tendon stressed initially to $\sigma_{p i}$ can be worked out at regular time intervals $\Delta t$ as (Au and $\mathrm{Si} 2009$ )

$$
\begin{gathered}
\bar{\varphi}_{s}(\Delta t)=\frac{-\Delta \sigma_{p r}(\Delta t)}{\sigma_{p i}+\Delta \sigma_{p r}(\Delta t) / 2} \\
\bar{\varphi}_{s}[(k+1) \Delta t]=\frac{\sigma_{p i} \bar{\varphi}_{s}(k \Delta t)}{\sigma_{p i}+\Delta \sigma_{p r}(\Delta t) / 2} \\
-\frac{\left[\Delta \sigma_{p r}[(k+1) \Delta t]-\Delta \sigma_{p r}(k \Delta t)\right]\left[1+\bar{\varphi}_{s}(\Delta t) / 2\right]-\Delta \sigma_{p r}(\Delta t) \bar{\varphi}_{s}[(k-1) \Delta t] / 2}{\sigma_{p i}+\Delta \sigma_{p r}(\Delta t) / 2} \\
-\frac{\sum_{i=2}^{n}\left[\Delta \sigma_{p r}(i \Delta t)-\Delta \sigma_{p r}[(i-1) \Delta t]\right]\left\{\bar{\varphi}_{s}[(k-i+2) \Delta t]-\bar{\varphi}_{s}[(n-i) \Delta t]\right\} / 2}{\sigma_{p i}+\Delta \sigma_{p r}(\Delta t) / 2}(k=1,2 \ldots n)
\end{gathered}
$$

Therefore, the equivalent creep coefficients of tendons can be obtained by a step-by-step procedure. Note that, although the creep coefficient $\bar{\varphi}_{s}(t)$ depends on $\sigma_{p i} l f_{p y}$, this parameter has been dropped for convenience in notation.

\subsection{ACl recommendations for modelling creep and shrinkage of concrete}

The prediction of creep and shrinkage effects in concrete structures as well as effects of various relevant variables related to material properties, climate and member size are provided in detail in a report by ACI committee 209 (1997). For brevity, it is referred to as ACI 209 hereafter. A summary of the recommendations is given below.

This report suggests that the compressive strength $f_{c}(t)(\mathrm{MPa})$ at age $t$ (days) can be expressed in terms of the corresponding value $f_{c}(28)(\mathrm{MPa})$ at age 28 days by

$$
f_{c}(t)=\frac{1}{a+b t} f_{c}(28)
$$

where the parameters $a$ and $b$ that depend on the cement type and method of curing are recommended in ACI 209. The modulus of elasticity of the concrete $E_{c}(t)(\mathrm{MPa})$ can be estimated from the compressive strength $f_{c}(t)$ and density of concrete $w\left(\mathrm{~kg} / \mathrm{m}^{3}\right)$ by

$$
E_{c}(t)=0.043\left[w^{3} f_{c}(t)\right]^{1 / 2}
$$

The creep coefficient $\varphi_{c}\left(t, t_{0}\right)$ at time $t$ (days) for a constant stress applied at the loading age $t_{0}$ (days) is

$$
\varphi_{c}\left(t, t_{0}\right)=\frac{\left(t-t_{0}\right)^{0.60}}{10+\left(t-t_{0}\right)^{0.60}} \varphi_{c u}
$$


where $\varphi_{c u}$ is the ultimate creep coefficient that, in the absence of specific data for local aggregates and material conditions, can be estimated as $\varphi_{c u}=2.35 \gamma_{c}$ in terms of the correction factor $\gamma_{c}$ related to ambient relative humidity, average thickness of the member or its volume-surface ratio, and temperature.

The recommended equation for prediction of shrinkage strain $\varepsilon_{s h}$ is

$$
\varepsilon_{s h}=\frac{t-t_{s}}{f+\left(t-t_{s}\right)}\left(\varepsilon_{s h}^{u}\right)
$$

where $f$ (days) is a constant dependent on curing conditions (i.e., 35 for moist cured concrete, 55 for steam cured concrete), $t_{s}$ is the age of concrete at initiation of drying (days), and $\varepsilon_{s h}^{u}$ is the ultimate shrinkage strain that, in the absence of shrinkage data, can be taken as $780 \gamma_{s h} \times 10^{-6} \mathrm{~m} / \mathrm{m}$ in terms of the correction factor $\gamma_{s h}$ related to ambient relative humidity, average thickness of the member or its volume-surface ratio, and temperature.

\subsection{Time integration method for time-dependent behaviour of cable-stayed bridges}

An accurate model taking into account the time-dependent behaviour of construction materials is indispensable for the accurate prediction of dynamic responses of cable-stayed bridges under various environmental and imposed loading many years after their completion. Based on the above equivalent creep model of tendons and other models for concrete creep and shrinkage, a finite element method in conjunction with time integration has been developed to predict the long-term behaviour of common concrete structures such as prestressed concrete girder bridges (Au and Si 2011).

When the finite element method is used to model a bridge, concrete members are usually represented as beam-column elements while tendons are idealized as truss elements connected to hypothetical rigid arms attached monolithically to the beam axis to ensure compatibility. Following the traditional finite element method, the incremental nodal load vector $\left\{\Delta q^{e}\right\}_{s}=\left[\Delta f_{1} \Delta f_{2}\right]_{s}^{T}$ of a tendon element for the time interval from $t$ to $(t+\Delta t)$ can be derived as

$$
\left\{\Delta q^{e}\right\}_{s}=[\bar{k}]_{s}\{\Delta u\}_{s}+\{\Delta f\}_{\varphi s}
$$

in terms of the stiffness matrix $[\bar{k}]_{s}$, incremental displacement vector $\{\Delta u\}_{s}$ and incremental load vector due to tendon creep $\{\Delta f\}_{\varphi s}$. Note that the variable $t$ has been omitted for brevity hereafter. The stiffness matrix $[\bar{k}]_{s}$ (Au and Si 2011) is given by

$$
[\bar{k}]_{s}=\frac{\bar{E}_{s}(\Delta t) A_{s}}{l_{s}}\left[\begin{array}{cc}
1 & -1 \\
-1 & 1
\end{array}\right]
$$

where $A_{s}$ is cross sectional area, $l_{s}$ is the length of tendon element, and $\bar{E}_{s}(\Delta t)$ is the mean modulus of elasticity over the time interval $\Delta t$ taking into account stress relaxation, which can be expressed in terms of the modulus of elasticity of the steel tendon $E_{s}$ as

$$
\bar{E}_{s}(\Delta t)=\frac{E_{s}}{1+\bar{\varphi}_{s}(\Delta t)}
$$

The incremental load vector due to cable relaxation $\{\Delta f\}_{\varphi s}$ is given by 


$$
\{\Delta f\}_{\varphi s}=\frac{\bar{E}_{s}(\Delta t)}{E_{s}}\left\{\left[\bar{\varphi}_{s}\left(t+\Delta t-t_{0}\right)-\bar{\varphi}_{s}\left(t-t_{0}\right)\right]\left\{\begin{array}{c}
\bar{N}_{s}\left(t_{0}\right) \\
-\bar{N}_{s}\left(t_{0}\right)
\end{array}\right\}+\int_{t_{0}}^{t}\left[\bar{\varphi}_{s}(t+\Delta t-\tau)-\bar{\varphi}_{s}(t-\tau)\right]\left\{\begin{array}{c}
\dot{\bar{N}}_{s}(\tau) \\
-\dot{\bar{N}}_{s}(\tau)
\end{array}\right\} d \tau\right\}
$$

where $\bar{N}_{s}\left(t_{0}\right)$ is the axial force of the element at time $t_{0}$ and $\dot{\bar{N}}_{s}(\tau)$ is the derivative of the axial force with respect to the dummy time variable $\tau$.

Similarly neglecting body forces, the incremental load vector of concrete beam-column element $\left\{\Delta q^{e}\right\}_{c}=\left[\Delta f_{1} \Delta f_{2} \cdots \Delta f_{12}\right]_{c}^{T}$ can be obtained as

$$
\left\{\Delta q^{e}\right\}_{c}=[\bar{k}]_{c}\{\Delta \delta\}_{c}+\{\Delta f\}_{\varphi c}+\{\Delta f\}_{c s}
$$

in terms of beam stiffness matrix $[\bar{k}]_{c}$, incremental displacement vector $\{\Delta \delta\}_{c}$, incremental load vector due to concrete creep $\{\Delta f\}_{\varphi c}$ and incremental load vector due to concrete shrinkage $\{\Delta f\}_{c s}$. Using the conventional finite element method, the stiffness matrix and the incremental load vector due to creep and shrinkage can be formulated in terms of the mean modulus of elasticity $\bar{E}_{c}$ and the mean modulus of rigidity of concrete $\bar{G}_{c}$ over the time step from $t$ to $(t+\Delta t)$, which can be expressed respectively as

$$
\begin{gathered}
\bar{E}_{c}(t)=\frac{\left[E_{c}(t)+E_{c}(t+\Delta t)\right] / 2}{1+\varphi_{c}(t+\Delta t, t) / 2} \\
\bar{G}_{c}(t)=\frac{\bar{E}_{c}(t)}{2\left(1+v_{c}\right)}
\end{gathered}
$$

where $v_{c}$ is the Poisson's ratio of concrete. Further details are available in Au and Si (2011).

\subsection{Modelling of cable-stayed bridges for free vibration analysis}

The analysis of concrete cable-stayed bridges taking into account time-dependent effects of concrete creep and shrinkage, and cable relaxation, as well as time-independent nonlinear effects including cable sag, large displacements, etc., has been reported by Curley and Shepherd (1996). A concrete cable-stayed bridge is first discretised using the finite element method. The bridge deck and towers are usually modelled as Bernoulli-Euler beam-column elements (Au et al. 2001). Each stay cable is modelled as either a single truss element with an effective modulus or a series of cable elements with the original modulus. One common practice to model a sagging cable is to use a single truss element with a length equal to that of its chord and an equivalent modulus of elasticity to allow for sag and elastic strain. A widely used expression (Au et al. 2001) for this equivalent modulus $E_{e q}$ is given by

$$
E_{e q}=\frac{E_{c a}}{1+\left(w H_{c a}\right)^{2} A_{c a} E_{c a} / 12 T^{3}}
$$

where $H_{c a}$ is the horizontal projected length, $A_{c a}$ is the cross-sectional area, $E_{c a}$ is the effective modulus of elasticity, $w$ is the weight per unit length and $T$ is the updated cable tension of the cable.

The main effect of large displacement is the "P-delta effect" in the bridge girders and towers. This 
is due to the coupling of large lateral deflections with high compressive axial forces. This coupling reduces both the axial and rotational stiffnesses of the corresponding members. An efficient approach to consider this effect is to adopt the geometric stiffness matrix $[k]_{G}$ of each beam-column element (McGuire et al. 2002) to modify its elastic stiffness matrix $[k]_{E}$. The resulting tangential stiffness matrix $[k]_{T}$ to be used as the element stiffness matrix in the analysis then becomes

$$
[k]_{T}=[k]_{E}+[k]_{G}
$$

After building up the local tangential stiffness matrix and consistent mass matrix of each element, they are transformed to the global coordinates system and assembled to form the global tangential stiffness matrix $[K]_{T}$ taking into account the effect of cable sag and large displacement as well as the global mass matrix $[M]$. Finally the governing equation for analysis of dynamic properties of an undamped cable-stayed bridge appears as

$$
\left([K]_{T}-\omega^{2}[M]\right)\{\bar{D}\}=\{0\}
$$

where $\omega$ is the circular frequency and $\{\bar{D}\}$ is the eigenvector.

The modulus of elasticity to be used in free vibration analysis is a key issue to address. Based on the principle of superposition, the total concrete strain $\varepsilon_{c}(t)$ due to the initial applied stress $\sigma_{c}\left(t_{0}\right)$, creep and shrinkage is given by Ghali et al. (2002) as

$$
\varepsilon_{c}(t)=\sigma_{c}\left(t_{0}\right)\left[\frac{1+\varphi_{c}\left(t, t_{0}\right)}{E_{c}\left(t_{0}\right)}\right]+\int_{0}^{\Delta \bar{\sigma}_{c}(t)} \frac{1+\varphi_{c}(t, \tau)}{E_{c}(\tau)} d \sigma_{c}(\tau)+\varepsilon_{c s}\left(t, t_{0}\right)
$$

where $\varphi_{c}\left(t, t_{0}\right)$ is the creep coefficient at time $t$ for concrete loaded at time $t_{0}, E_{c}(t)$ is the modulus of elasticity of concrete at time $t, \Delta \bar{\sigma}_{c}(t)$ is the stress increment from time $t_{0}$ to $t$ and $\varepsilon_{c s}\left(t, t_{0}\right)$ is the free shrinkage from time $t_{0}$ to $t$. To predict the long-term performance of concrete structures efficiently, one may rewrite Eq. (18) for convenience as

$$
\varepsilon_{c}(t)=\sigma_{c}\left(t_{0}\right)\left[\frac{1+\varphi_{c}\left(t, t_{0}\right)}{E_{c}\left(t_{0}\right)}\right]+\frac{\Delta \bar{\sigma}_{c}(t)}{\bar{E}_{c}\left(t, t_{0}\right)}+\varepsilon_{c s}\left(t, t_{0}\right)
$$

where the age-adjusted elasticity modulus (AAEM) $\bar{E}_{c}\left(t, t_{0}\right)$ to be used in the calculation of the total strain increment, instantaneous plus creep, due to a stress increment of magnitude developing gradually from zero to a value $\Delta \bar{\sigma}_{c}(t)$ is given by in terms of an ageing coefficient $\chi_{c}\left(t, t_{0}\right)$ as

$$
\bar{E}_{c}\left(t, t_{0}\right)=\frac{E_{c}\left(t_{0}\right)}{1+\chi_{c}\left(t, t_{0}\right) \varphi_{c}\left(t, t_{0}\right)}
$$

In other words, the AAEM takes into account the long-term deformation of concrete, primarily creep, over the period from time $t_{0}$ to $t$ as a matter of years, which explains why it gradually drops with time. Therefore it is obvious that the free vibration analysis of a concrete bridge at time $t$ many years after completion, which involves variations of structural responses within fractions of a second, should be based on the instantaneous modulus of elasticity of concrete $E_{c}(t)$ then, instead of the AAEM from time $t_{0}$ to $t$ as in some previous work. 


\subsection{Finite element implementation}

The three-dimensional free vibration analysis of concrete cable-stayed bridges considering geometrically nonlinearity and time-dependent behaviour can be carried out in accordance with the flowchart shown in Fig. 1 as explained below:

a) The finite element model of the cable-stayed bridge is built up first. The bridge girder and towers are represented by beam-column elements taking into account geometric nonlinearities. Each stay cable is modelled as a single truss element considering cable sag under its own weight. The prestressing tendons in the concrete girder are modelled with truss elements attached to the girder axis with rigid arms to approximate the tendon profiles.

b) The time-dependent analysis from completion of the cable-stayed bridge to the time of interest is carried out using the established finite element model by time integration taking into account creep, shrinkage and ageing of concrete, and stress relaxation in prestressing tendons and stay cables. The prevalent bridge geometry and internal forces at the time of interest will then be noted.

c) The finite element model at the time of interest is updated using the bridge geometry and internal forces obtained from the time-dependent analysis. In particular, the global tangential matrix and global mass matrix are based on the updated model and the instantaneous Young's modulus of each material at the time of interest.

d) Free vibration analysis of the bridge is then carried out using subspace iteration method or

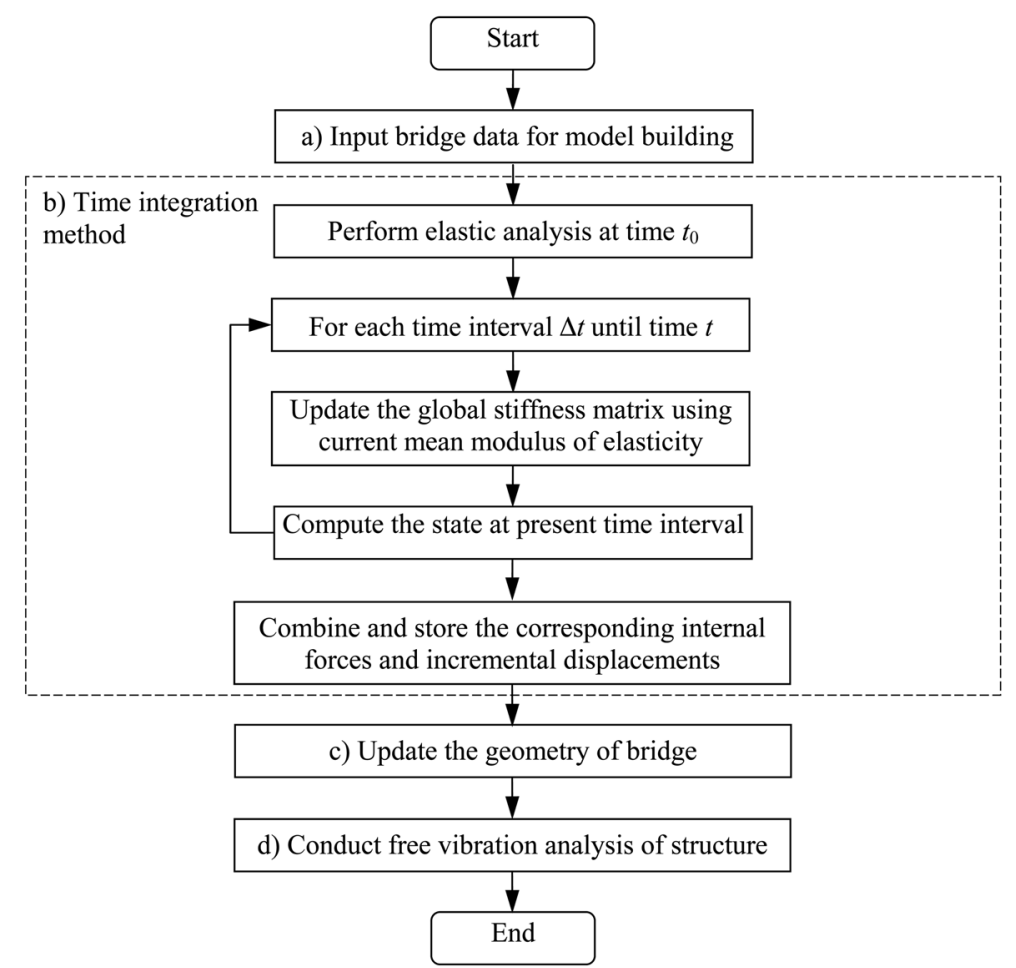

Fig. 1 Flowchart for free vibration analysis of cable-stayed bridges taking into account time-dependent behaviour 
similar based on the updated global stiffness and mass matrices to obtain the natural frequencies and modal shapes.

\section{Case studies}

\subsection{Dynamic properties of a cable-stayed concrete cantilever considering time-dependent behaviour}

The dynamic properties of a hypothetical cable-stayed concrete cantilever as shown in Fig. 2 under long-term effects are studied using the proposed method. The cantilever is adapted from an example provided by Ghali et al. (2002). It is $10 \mathrm{~m}$ in length with a square cross section of $1 \mathrm{~m} \times 1 \mathrm{~m}$. Its unit weight is $25 \mathrm{kN} / \mathrm{m}^{3}$. The characteristic compressive strength of concrete is $f_{c k}=36 \mathrm{MPa}$. Moist curing is carried out until $T_{s}=3$ days after which shrinkage begins. The relative humidity is taken as $70 \%$ throughout. For the concrete in the cantilever, it is assumed that Type I cement is used, the water cement ratio is 0.45 and the percentage of fine aggregates is $60 \%$. The stay cable is a stress relieved tendon with a cross sectional area $A_{s}=250 \mathrm{~mm}^{2}$, Young's Modulus $E_{s}=195 \mathrm{GPa}$, and unit weight $\rho_{s}=78 \mathrm{kN} / \mathrm{m}^{3}$. The initial tension $P_{0}=210 \mathrm{kN}$ is applied at time $t_{0}=28$ days with reference to the age of cantilever. The initial prestressing ratio $\sigma_{p i} / f_{p y}$ is taken as 0.8 , which is unusually high to demonstrate the effect of relaxation. The parameters of ACI 209 (1997) are adopted for analysis. In view of the relatively small dimensions of the structure, the sag effect of cable and geometric nonlinearities of the cantilever are ignored. The cantilever is modelled by 4 identical beam-column elements while the cable is modelled by a truss element. First, the initial natural frequencies of this structure at Day 28 are calculated without accounting for any timedependent behaviour. Then the dynamic properties of global vibrations at Day 300 are calculated. To investigate the effects of various sources of time-dependent deformation, a few hypothetical cases are worked out, namely (a) Case A: concrete ageing only; (b) Case B: concrete ageing and cable relaxation only; (c) Case C: concrete ageing, creep and shrinkage, and cable relaxation; and (d) Case D: cable relaxation only.

The percentage losses of cable tension with time in Cases C and D are shown in Fig. 3. The other internal forces also vary accordingly. The first three frequencies and their percentage differences from the initial frequencies are shown in Table 1. Comparing results of various cases with the initial

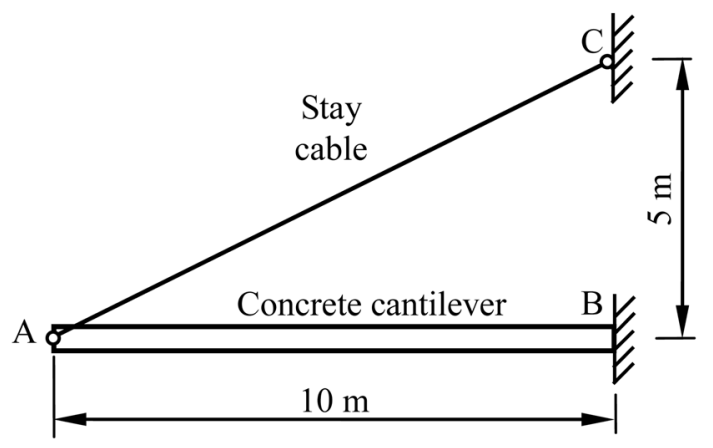

Fig. 2 A cable-stayed cantilever 
Table 1 Global dynamic properties of cable-stayed cantilever at Day 300

\begin{tabular}{|c|c|c|c|c|c|c|c|c|c|}
\hline \multirow[b]{2}{*}{ Mode } & \multirow{2}{*}{$\begin{array}{l}\text { Initial } \\
\text { freq. } \\
(\mathrm{Hz})\end{array}$} & \multicolumn{2}{|c|}{ Case A } & \multicolumn{2}{|c|}{ Case B } & \multicolumn{2}{|c|}{ Case C } & \multicolumn{2}{|c|}{ Case D } \\
\hline & & $\begin{array}{r}\text { Freq. } \\
(\mathrm{Hz})\end{array}$ & $\begin{array}{c}\text { Diff. } \\
(\%)\end{array}$ & $\begin{array}{r}\text { Freq. } \\
(\mathrm{Hz})\end{array}$ & $\begin{array}{c}\text { Diff. } \\
(\%)\end{array}$ & $\begin{array}{r}\text { Freq. } \\
(\mathrm{Hz})\end{array}$ & $\begin{array}{c}\text { Diff. } \\
(\%)\end{array}$ & $\begin{array}{r}\text { Freq. } \\
(\mathrm{Hz})\end{array}$ & $\begin{array}{c}\text { Diff. } \\
(\%)\end{array}$ \\
\hline 1 & 6.453 & 6.664 & 3.26 & 6.664 & 3.26 & 6.666 & 3.31 & 6.453 & 0.00 \\
\hline 2 & 38.842 & 40.220 & 3.55 & 40.220 & 3.55 & 40.237 & 3.59 & 38.842 & 0.00 \\
\hline 3 & 109.071 & 112.949 & 3.56 & 112.949 & 3.56 & 112.994 & 3.60 & 109.071 & 0.00 \\
\hline
\end{tabular}

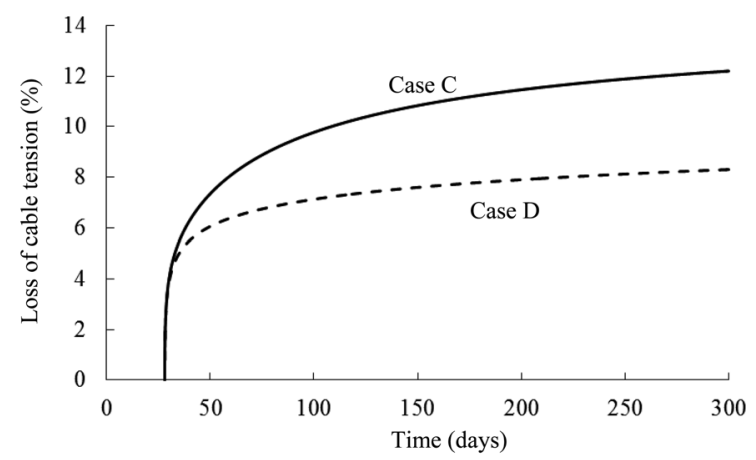

Fig. 3 Percentage losses of cable tension with time in Cases $\mathrm{C}$ and $\mathrm{D}$

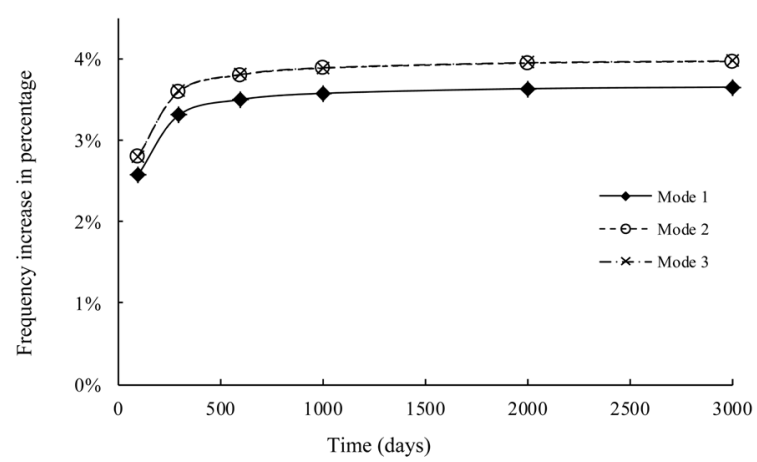

Fig. 4 Frequency increase with time due to effects of time-dependent behaviour

results shows that the natural frequencies increase slightly under concrete ageing effect and its combination with other time-dependent deformations, while cable relaxation has little additional effect. It is also observed that concrete ageing has the most important influence on the long-term dynamic properties among various time-varying factors by comparing Cases $\mathrm{A}, \mathrm{B}$ and $\mathrm{C}$. Comparing results of Cases $\mathrm{B}$ and $\mathrm{C}$ demonstrates that the interaction among concrete ageing, creep and shrinkage has more effect on the dynamic characteristics than the interaction between concrete ageing and cable relaxation. Comparison of the results of various cases also shows that the interaction among various time-varying factors is greater than their individual effects. Therefore it is desirable to take into account the interaction among various time-varying factors when long-term analysis of dynamic behaviour is performed. One important observation is that all the frequencies go up primarily because of concrete ageing, namely the gradual increase in modulus of elasticity of concrete.

Fig. 4 shows that the first three frequencies of the structure increase gradually with time under the effects of cable relaxation, and ageing, creep and shrinkage of concrete. The combined timedependent behaviour increases the frequencies by up to $3.6 \%$ within the first year after completion. In particular, the frequencies increase relatively rapidly in the first year but tend to become stable after a few years.

\subsection{Dynamic properties of a cable-stayed bridge considering time-dependent behaviour}

A typical modified fan cable-stayed concrete bridge similar to that studied by Au et al. (2001) with a main span of $364 \mathrm{~m}$, as shown in Fig. 5, is modelled as a two-dimensional structural system 


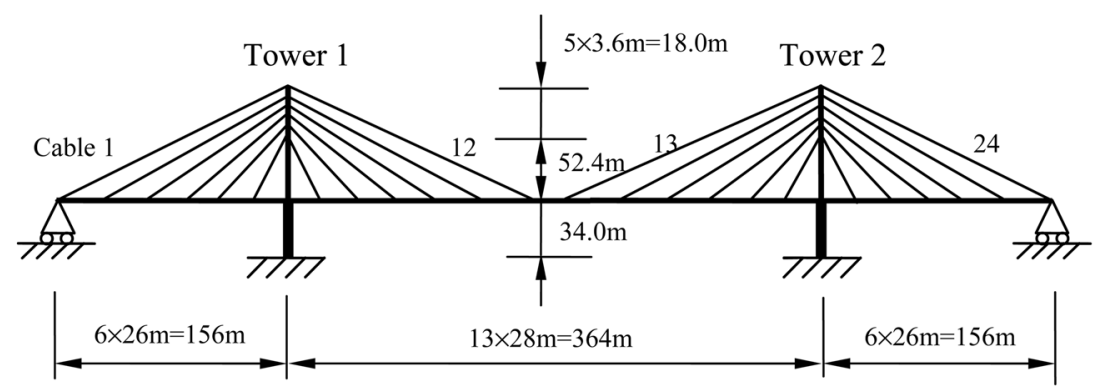

(a) Bridge geometry
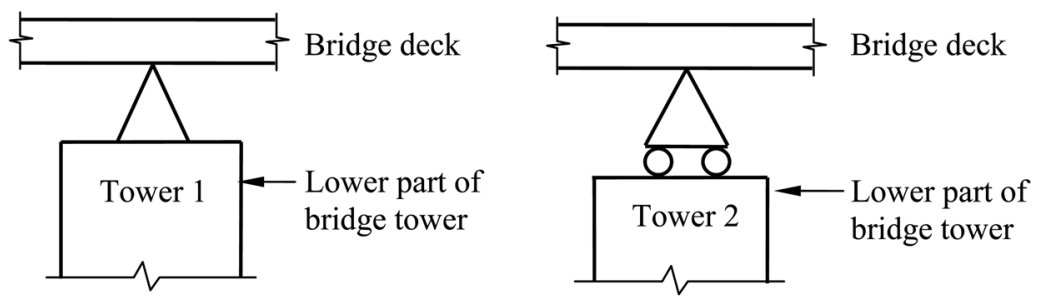

(b) Connection details between bridge deck and lower part of bridge tower

Fig. 5 Schematic structural arrangement of a typical concrete cable-stayed bridge

for dynamic analysis. The bridge deck is hinge-supported on Tower 1 but roller-supported on Tower 2. The corresponding properties of the bridge deck and towers are given in Table 2. The properties of stay cables and the finite element discretisation are shown in Tables 3 and 4 . The cable forces are

Table 2 Properties of deck and towers of cable-stayed bridge

\begin{tabular}{lcccc}
\hline \hline \multicolumn{1}{c}{ Part of structures } & $\begin{array}{c}\text { Cross sectional } \\
\text { area } \\
A\left(\mathrm{~m}^{2}\right)\end{array}$ & $\begin{array}{c}\text { Second moment of } \\
\text { area } \\
I\left(\mathrm{~m}^{4}\right)\end{array}$ & $\begin{array}{c}\text { Young's modulus of } \\
\text { concrete at Day 28 } \\
E_{c 28}(\mathrm{MPa})\end{array}$ & $\begin{array}{c}\text { Density } \\
\rho\left(\mathrm{kg} / \mathrm{m}^{3}\right)\end{array}$ \\
\hline Bridge deck & 6.00 & 4.19 & 32090 & 2550 \\
Bridge tower-above & 14.2 & 30.0 & 32090 & 2550 \\
Bridge tower-below deck & 35.8 & 40.0 & 32090 & 2550 \\
\hline
\end{tabular}

Table 3 Cross sectional areas of stay cables of cable-stayed bridge

\begin{tabular}{cccc}
\hline \hline Cable no. & Area $\left(\mathrm{m}^{2}\right)$ & Cable no. & Area $\left(\mathrm{m}^{2}\right)$ \\
\hline $1 \& 24$ & 0.060 & $7 \& 18$ & 0.013 \\
$2 \& 23$ & 0.023 & $8 \& 17$ & 0.016 \\
$3 \& 22$ & 0.020 & $9 \& 16$ & 0.019 \\
$4 \& 21$ & 0.017 & $10 \& 15$ & 0.023 \\
$5 \& 20$ & 0.014 & $11 \& 14$ & 0.026 \\
$6 \& 19$ & 0.011 & $12 \& 13$ & 0.029 \\
\hline
\end{tabular}


Table 4 Discretisation scheme of a cable-stayed bridge

\begin{tabular}{lcc}
\hline \hline Components & $\begin{array}{c}\text { No. of } \\
\text { elements }\end{array}$ & Scheme \\
\hline Deck & 26 & Length from left to right ends: $6 \times 26 \mathrm{~m}, 6 \times 28 \mathrm{~m}, 2 \times 14 \mathrm{~m}, 6 \times 28 \mathrm{~m}, 6 \times 26 \mathrm{~m}$ \\
Tower & 11 & Length from bottom to top: $3 \times 11.33 \mathrm{~m}, 3 \times 17.47 \mathrm{~m}, 5 \times 3.6 \mathrm{~m}$ \\
Cable & 1 & Whole length of each cable \\
\hline
\end{tabular}

adjusted by iterations so that the deck and tower geometry under permanent loading is that as shown in Fig. 5. The working stress ratios $\sigma_{p i} / f_{p y}$ of the stay cables are kept low enough so that cable relaxation is negligible, like what is normally adopted in practical cable-stayed bridges. However in view of the much larger dimensions, the sag effect of cables is always taken into account by the use of equivalent modulus $E_{e q}$. Some simplifying assumptions are made in this study which focuses on the effects of time-dependent behaviour on the dynamic properties of cable-stayed bridges. It is assumed that the bridge is constructed over a short period of time and the construction sequence can be ignored. The characteristic compressive strength of the concrete used in the deck and towers is $f_{c k}=40 \mathrm{MPa}$. Wet curing is carried out until $T_{s}=3$ days after which shrinkage begins. The parameters of ACI 209 (1997) are adopted. The relative humidity is taken as $80 \%$ throughout. For the concrete in the deck and towers, it is assumed that Type I cement is used, the water cement ratio is 0.45 and the percentage of fine aggregates is $60 \%$.

A few hypothetical cases are worked out. Firstly, the initial natural frequencies of global vibrations of the bridge at Day 28 are calculated without considering geometric nonlinearities of the deck and towers and any time-dependent behaviour. Secondly, the natural frequencies at Day 28 are obtained considering geometric nonlinearities (Case A). Then the dynamic properties at Day 300 are obtained for various cases considering geometric nonlinearities, namely (a) Case B: concrete ageing only; (b) Case C: concrete ageing and creep only; and (c) Case D: concrete ageing, concrete creep and shrinkage. The first ten natural frequencies and the percentage changes compared with the initial values are shown in Table 5 and Fig. 6 respectively.

Table 5 The first ten natural global frequencies $(\mathrm{Hz})$ of cable-stayed bridge

\begin{tabular}{cccccc}
\hline \hline Mode & Initial (Day 28) & Case A (Day 28) & Case B (Day 300) & Case C (Day 300) & Case D (Day 300) \\
\hline 1 & 0.337 & 0.335 & 0.339 & 0.341 & 0.343 \\
2 & 0.461 & 0.454 & 0.461 & 0.465 & 0.470 \\
3 & 0.687 & 0.676 & 0.684 & 0.687 & 0.689 \\
4 & 0.748 & 0.739 & 0.746 & 0.747 & 0.749 \\
5 & 0.839 & 0.826 & 0.836 & 0.840 & 0.846 \\
6 & 1.047 & 1.028 & 1.047 & 1.051 & 1.061 \\
7 & 1.219 & 1.202 & 1.230 & 1.226 & 1.230 \\
8 & 1.281 & 1.256 & 1.283 & 1.281 & 1.282 \\
9 & 1.338 & 1.313 & 1.342 & 1.340 & 1.347 \\
10 & 1.389 & 1.373 & 1.408 & 1.418 & 1.426 \\
\hline
\end{tabular}




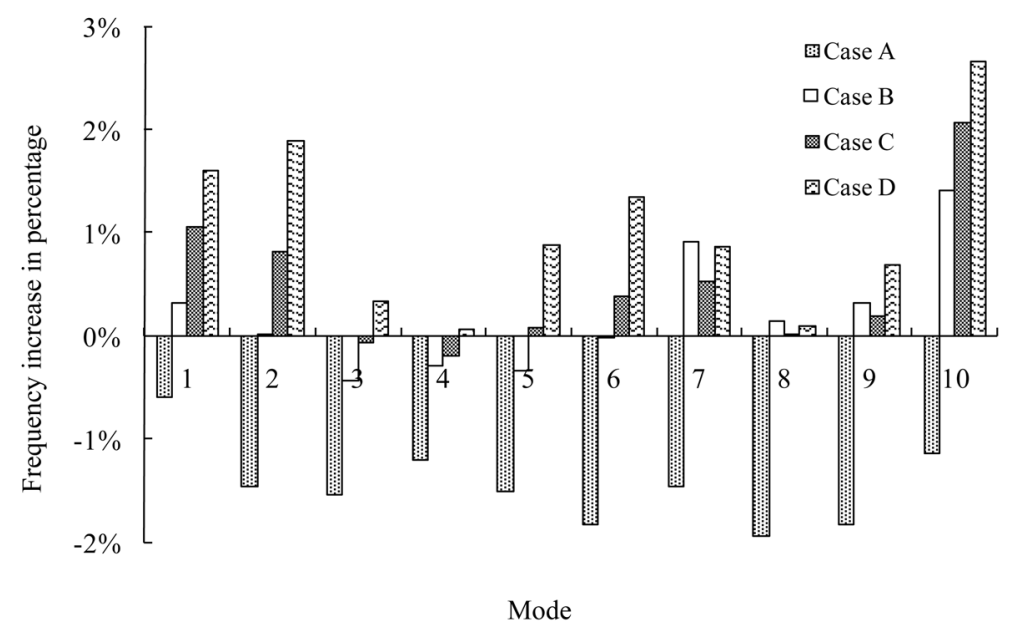

Fig. 6 Variation of the first 10 frequencies for various hypothetical cases

Table 5 and Fig. 6 show that geometric nonlinearities tend to reduce the natural frequencies by a maximum of $1.94 \%$. However, the natural frequencies increase under the combined effects of timedependent behaviour and geometric nonlinearities by a maximum of $2.66 \%$. It indicates that the time-dependent behaviour more than offsets the effects of geometric nonlinearities on dynamic properties of this bridge. Comparing Cases B, C and D shows that concrete ageing plays an important role in increasing the long-term natural frequencies. The effects of creep are higher than those of shrinkage. The interaction between concrete creep and ageing effects should therefore be considered carefully for long-term analyses of concrete structures.

Fig. 7 shows that the frequencies of the first 10 modes of this bridge increase with time with respect to Case A under the time-dependent effects of ageing, creep and shrinkage of concrete coupled with geometric nonlinearities. It is also observed that the time-dependent behaviour has different effects on various frequencies of the bridge, ranging from $1.42 \%$ to $4.37 \%$ at Day 3,000 . It further confirms that time-dependent behaviour increases the natural frequencies of this concrete

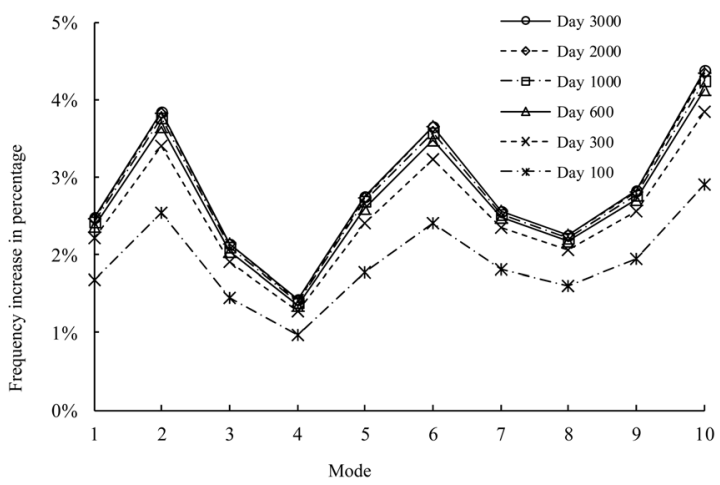

(a) Variation of frequencies of the first 10 modes

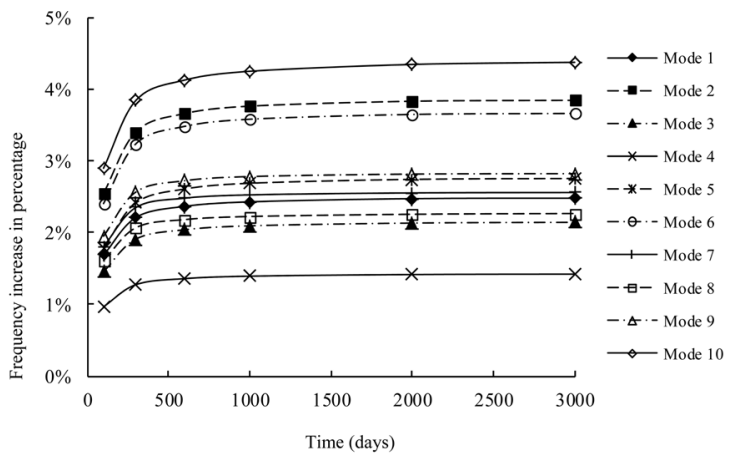

(b) Variation of the first 10 frequencies with time

Fig. 7 Variation of the first 10 frequencies with time under all time-dependent effects 
bridge. It is therefore obvious that the long-term behaviour of concrete and its interaction with geometric nonlinearities should be properly taken into account for reliable damage identification in any vibration-based structural health monitoring systems.

\subsection{Effects of cable relaxation on dynamic properties of cable-stayed girders with multiple cables}

To investigate particularly the effects of cable relaxation on cable-stayed girders with multiple cables, the cable-stayed cantilever shown in Fig. 8 and the cable-stayed girder with a hinged end shown in Fig. 9 are further considered. Each of them is supported by two stay cables such that their initial cable forces provide the vertical reactions to the deck when considered as a continuous beam with the cable supports replaced by roller supports. The cable lengths have been adjusted by iteration so that the initial vertical deflections at deck level cable anchorages are effectively zero. The cross sectional areas of stay cables are then adjusted such that the initial prestressing ratios $\sigma_{p i} / f_{p y}$ all have a relatively high value of 0.8 . The properties of the concrete girders and other assumptions are the same as those in the example in Section 3.1. The weight of concrete girder is supported by falsework until the time $t_{0}=28$ days with reference to the age of concrete when the cables are tensioned. The cross sectional areas of cables and initial cable forces are determined accordingly and shown in Tables 6 and 7. The girder is modelled by 8 identical beam-column elements while each cable is modelled by a truss element.

To investigate the effects of various sources of time-dependent deformation, a few hypothetical cases are studied, namely (a) Case A: concrete ageing only; (b) Case B: concrete ageing and cable relaxation only; (c) Case C: concrete ageing, creep and shrinkage, and cable relaxation; and (d)

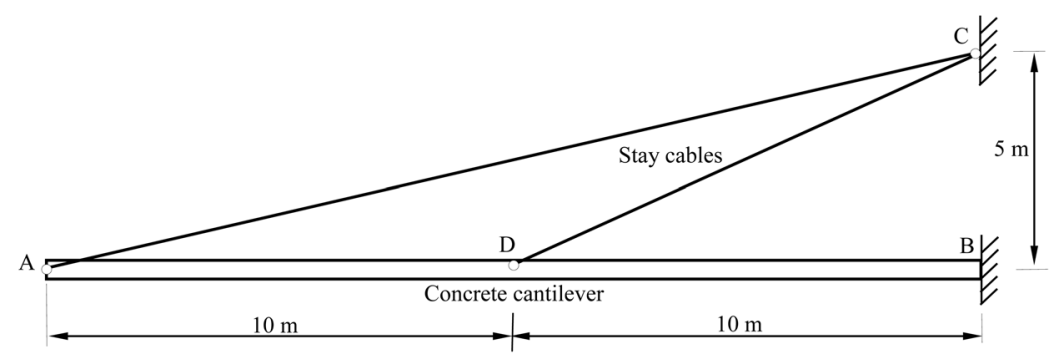

Fig. 8 A cable-stayed cantilever with two cables

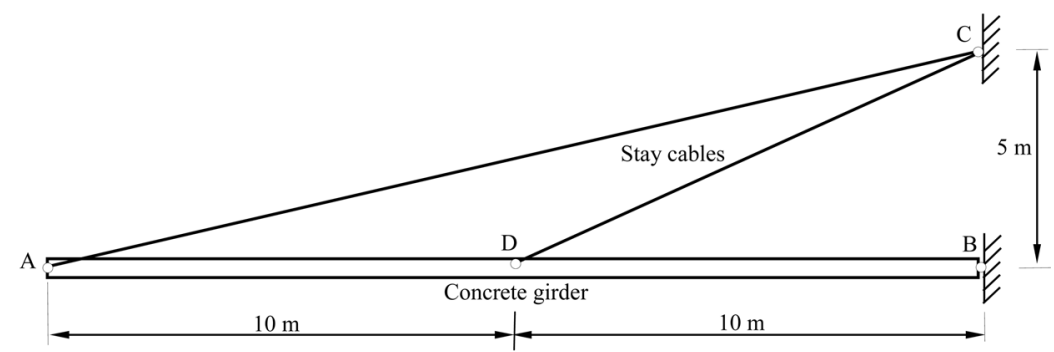

Fig. 9 A cable-stayed girder with two cables and a hinged end 
Table 6 Cable-stayed cantilever with two cables

\begin{tabular}{|c|c|c|c|c|}
\hline \multirow{2}{*}{ Cable } & \multirow{2}{*}{$\begin{array}{l}\text { Sectional area } \\
\left(\mathrm{mm}^{2}\right)\end{array}$} & \multirow{2}{*}{$\begin{array}{l}\text { Initial cable force at } \\
\text { Day } 28(\mathrm{kN})\end{array}$} & \multicolumn{2}{|c|}{ Case $\mathrm{C}$ at Day 300} \\
\hline & & & Loss in cable force (\%) & Deflection at anchorage $(\mathrm{mm})$ \\
\hline $\mathrm{AC}$ & 488 & 409.8 & 10.5 & 18.1 \\
\hline $\mathrm{DC}$ & 763 & 641.0 & 9.1 & 6.2 \\
\hline
\end{tabular}

Table 7 Cable-stayed girder with a hinged end and two cables

\begin{tabular}{|c|c|c|c|c|}
\hline \multirow{2}{*}{ Cable } & \multirow{2}{*}{$\begin{array}{l}\text { Sectional area } \\
\left(\mathrm{mm}^{2}\right)\end{array}$} & \multirow{2}{*}{$\begin{array}{c}\text { Initial cable force at } \\
\text { Day } 28(\mathrm{kN})\end{array}$} & \multicolumn{2}{|c|}{ Case C at Day 300} \\
\hline & & & Loss in cable force (\%) & Deflection at anchorage $(\mathrm{mm})$ \\
\hline $\mathrm{AC}$ & 468 & 392.9 & 4.5 & 43.7 \\
\hline $\mathrm{DC}$ & 833 & 700.1 & -2.7 & 21.1 \\
\hline
\end{tabular}

Case D: cable relaxation only. The variations of cable forces and deflections at anchorage in Case C at Day 300 shown in Tables 6 and 7 will shed light on the behaviour of the girders. Because of the relatively high stiffness of the concrete cantilever, relaxation of cables gives rise to relatively high losses in cable forces but relatively little deck deflections. However, the girder with a hinged end has relatively little constraints against displacement, in particular the bodily rotation about the hinged end. Relaxation of cables causes relatively large deflections and substantial redistribution of cable forces, including increase in force in the interior cable.

The dynamic properties of global vibrations at Day 300 are also calculated. The first three frequencies and their percentage differences from the initial frequencies are shown in Tables 8 and 9 for the cantilever and girder with hinged end respectively. Comparing results of various cases with the initial results shows that conclusions drawn in Section 3.1 for the natural frequencies are

Table 8 Global dynamic properties of cable-stayed cantilever with two cables at Day 300

\begin{tabular}{cccccccccc}
\hline \hline \multirow{2}{*}{ Mode } & $\begin{array}{c}\text { Initial } \\
\text { freq. }\end{array}$ & \multicolumn{2}{c}{ Case A } & \multicolumn{2}{c}{ Case B } & \multicolumn{2}{c}{ Case C } & \multicolumn{2}{c}{ Case D } \\
\cline { 3 - 10 } & $(\mathrm{Hz})$ & $\begin{array}{c}\text { Freq. } \\
(\mathrm{Hz})\end{array}$ & $\begin{array}{c}\text { Diff. } \\
(\%)\end{array}$ & $\begin{array}{c}\text { Freq. } \\
(\mathrm{Hz})\end{array}$ & $\begin{array}{c}\text { Diff. } \\
(\%)\end{array}$ & $\begin{array}{c}\text { Freq. } \\
(\mathrm{Hz})\end{array}$ & $\begin{array}{c}\text { Diff. } \\
(\%)\end{array}$ & $\begin{array}{c}\text { Freq. } \\
(\mathrm{Hz})\end{array}$ & $\begin{array}{c}\text { Diff. } \\
(\%)\end{array}$ \\
\hline 1 & 1.880 & 1.925 & 2.42 & 1.925 & 2.41 & 1.926 & 2.44 & 1.880 & -0.01 \\
2 & 9.837 & 10.175 & 3.44 & 10.175 & 3.44 & 10.179 & 3.48 & 9.837 & 0.00 \\
3 & 27.122 & 28.086 & 3.55 & 28.085 & 3.55 & 28.098 & 3.60 & 27.122 & 0.00 \\
\hline
\end{tabular}

Table 9 Global dynamic properties of cable-stayed girder with a hinged end and two cables at Day 300

\begin{tabular}{cccccccccc}
\hline \hline \multirow{2}{*}{ Mode } & $\begin{array}{c}\text { Initial } \\
\text { freq. } \\
(\mathrm{Hz})\end{array}$ & \multicolumn{2}{c}{ Case A } & \multicolumn{2}{c}{ Freq. } \\
$(\mathrm{Hz})$ & $\begin{array}{c}\text { Diff. } \\
(\%)\end{array}$ & $\begin{array}{c}\text { Freq. } \\
(\mathrm{Hz})\end{array}$ & $\begin{array}{c}\text { Diff. } \\
(\%)\end{array}$ & $\begin{array}{c}\text { Freq. } \\
(\mathrm{Hz})\end{array}$ & $\begin{array}{c}\text { Diff. } \\
(\%)\end{array}$ & $\begin{array}{c}\text { Freq. } \\
(\mathrm{Hz})\end{array}$ & $\begin{array}{c}\text { Diff. } \\
(\%)\end{array}$ \\
\hline 1 & 1.210 & 1.211 & 0.07 & 1.210 & 0.01 & 1.210 & 0.00 & 1.209 & -0.07 \\
2 & 6.951 & 7.186 & 3.37 & 7.185 & 3.37 & 7.188 & 3.41 & 6.951 & 0.00 \\
3 & 21.973 & 22.753 & 3.55 & 22.753 & 3.55 & 22.763 & 3.60 & 21.973 & 0.00 \\
\hline
\end{tabular}


generally valid even for cable-stayed girders with multiple cables acting at high initial prestressing ratios. In particular, changes in frequencies in Case D show that the effect of cable relaxation is negligible. The effects of time-dependent behaviour on global dynamic properties of cable-stayed bridges are essentially through changes in instantaneous stiffness as well as geometric stiffness resulting from changes in geometry. The time-dependent factors of concrete ageing, creep and shrinkage, and cable relaxation all contribute to minor changes in geometry and hence minor changes in dynamic properties. A more significant effect is concrete ageing which gradually increases the instantaneous stiffness of concrete members. An exception to this is the first mode of the cablestayed girder with hinged end, which results largely from rotation of the girder about the hinged end. One may also note that the instantaneous material stiffness of steel cables remains unchanged with time, which explains why the effects of cable relaxation on global dynamic properties are relatively small.

To provide better understanding of the overall dynamic behaviour, the local cable vibrations in Case $\mathrm{C}$ of the cable-stayed cantilever with two cables are worked out. Assuming that bare steel cables are used, the initial frequencies of local vibrations of cables AC and DC are $7.958 \mathrm{~Hz}$ and 14.677 $\mathrm{Hz}$ respectively, which will decrease to $7.529 \mathrm{~Hz}$ and $13.994 \mathrm{~Hz}$ respectively at Day 300 because of various time-dependent effects. The local cable frequencies tend to be higher than the global structural frequencies. Moreover, the opposing trends of global structural frequencies and local cable frequencies can be explained by the fact that the former result from the holistic structural behaviour while the latter are governed by cable forces.

\section{Further verification}

To further verify the above numerical findings, an experiment has been conducted to monitor the long-term development of dynamic properties of a simply supported post-tensioned concrete beam of length $2100 \mathrm{~mm}$, span $2000 \mathrm{~mm}$, breadth $100 \mathrm{~mm}$ and depth $150 \mathrm{~mm}$. The concrete had cylinder strength of $54.2 \mathrm{MPa}$ and Young's modulus of $24764 \mathrm{MPa}$ at Day 21. An initial prestressing force of $100 \mathrm{kN}$ was applied at Day 14 by a straight 7-wire super strand of $12.9 \mathrm{~mm}$ diameter with 25 $\mathrm{mm}$ eccentricity. The preliminary results of the frequency of the first mode in Fig. 10 clearly show an upward trend, confirming the dominant effect of concrete ageing compared with other factors.

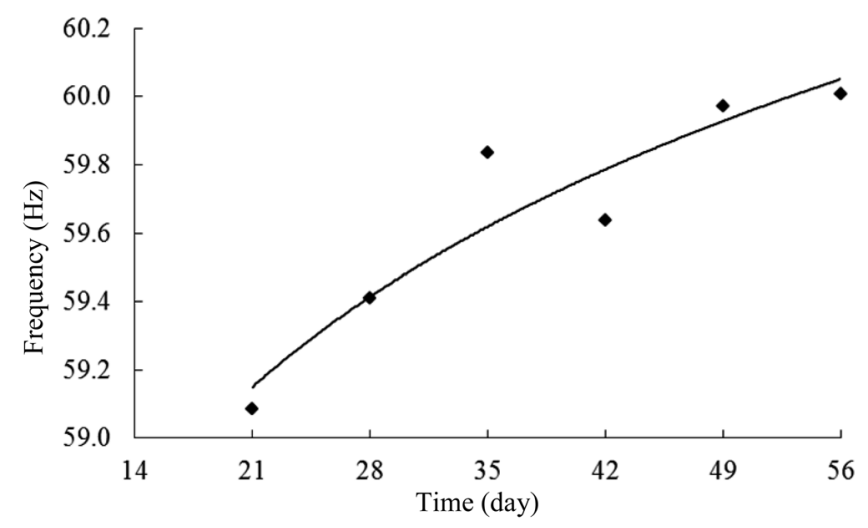

Fig. 10 Variation of frequency of first mode of a post-tensioned beam 
However, the validity of the numerical model presented is only as good as the models for creep and shrinkage of concrete and relaxation of steel tendons. Actually Neville (2004) and Brooks (2005) have presented experimental results of more than 20 years to show the increase of concrete strength and modulus of elasticity with time. Therefore it is expected that the presented model will also be valid for a long time until the structure suffers from damage, corrosion, etc.

\section{Conclusions}

A systematic and efficient method is proposed to investigate the dynamic properties of cable-stayed bridges considering the effects of long-term time-dependent behaviour due to concrete ageing, creep and shrinkage together with any possible cable relaxation. The proposed time integration method can cope with time-dependent finite element analyses of cable-stayed bridges by proper use of the time-dependent constitutive model of concrete and the equivalent creep model for cables while taking account of various geometric nonlinearities. Free vibration analysis for the time of interest can be carried out by means of subspace iteration method or similar based on the instantaneous material properties, and the updated internal forces and geometry of the bridge then. Numerical examples are presented to illustrate the application of the proposed method as well as to investigate the behaviour of typical cable-stayed concrete bridges. Results show that, although geometric nonlinearities tend to reduce the natural frequencies, the time-dependent behaviour of concrete more than offsets it and tends to increase the natural frequencies in the long run. Therefore, whether accounting for the geometric nonlinearities or not, the estimated natural frequencies of such structures increase gradually with time due to concrete ageing effect alone, its interaction with creep and shrinkage of concrete, and cable relaxation, or their combined effects. Furthermore, it is found that cable relaxation has comparatively little effect on the natural frequencies. These results also indicate that concrete ageing has the most important influence on the dynamic properties among various time-varying factors. The interaction between concrete ageing effect and effect of concrete creep, cable relaxation or their combined effects are generally greater than their individual effects. Hence the interaction among various time-varying factors should be considered carefully during long-term dynamic analyses of concrete cable-stayed bridges. Besides, the effect of time-dependent behaviour on dynamic properties varies from mode to mode. Therefore, the long-term variations of dynamic characteristics due to time-dependent behaviour should be investigated in detail in order to ensure reliable damage identification in any vibration-based structural health monitoring systems.

\section{Acknowledgements}

The work described in this paper has been supported by the Research Grants Council (RGC) of the Hong Kong Special Administrative Region, China (RGC Project No. HKU 7102/08E).

\section{References}

Aalami, B.O. (1998), "Time-dependent analysis of concrete structures", Prog. Struct. Eng. Mater., 1(4), $384-391$. ACI Committee 209 (1997), Prediction of creep, shrinkage and temperature effects in concrete structures, 
American Concrete Institution.

Au, F.T.K., Cheng, Y.S., Cheung, Y.K. and Zheng, D.Y. (2001), "On the determination of natural frequencies and mode shapes of cable-stayed bridges", Appl. Math. Model., 25, 1099-1115.

$\mathrm{Au}$, F.T.K., Liu, C.H. and Lee, P.K.K. (2009), "Creep and shrinkage analysis of reinforced concrete frames by history-adjusted and shrinkage-adjusted elasticity moduli”, Struct. Des. Tall Spec. Build., 18(1), 13-35.

$\mathrm{Au}$, F.T.K. and Si, X.T. (2009), Time-dependent analysis of frames taking into account creep, shrinkage and cable relaxation, 7th International Conference on Tall Buildings Hong Kong, Research Publishing, 649-658.

$\mathrm{Au}$, F.T.K. and Si, X.T. (2011), "Accurate time-dependent analysis of concrete bridges considering concrete creep, concrete shrinkage and cable relaxation", Eng. Struct., 33(1), 118-126.

Brooks, J.J. (2005), "30-year creep and shrinkage of concrete", Mag. Concrete Res., 57(9), 545-556.

Doebling, S.W., Farrar, C.R., Prime, M.B. and Shevitz, D.W. (1996), "Damage Identification and health monitoring of strutural and Mechanical systems from changes in their dynamic characteristics: a literature review”, Technical Report, DOI: 10.2172/249299.

Elbadry, M.M. and Ghali, A. (2001), "Analysis of time-dependent effects in concrete structures using conventional linear computer programs", Can. J. Civil Eng., 28(2), 190-200.

Ghali, A., Favre, R. and Elbadry, M.M. (2002), Concrete Structures: Stresses and Deformations, $3^{\text {rd }}$ Edition, Spon Press, London.

Kim, C.W., Kawatani, M., Ozaki, R. and Makihata, N. (2011), "Recovering missing data transmitted from a wireless sensor node for vibration-based bridge health monitoring", Struct. Eng. Mech., 38(4), 417-428.

Kmet, S., Tomko, M. and Brda, J. (2011), "Time-dependent analysis of cable trusses Part II. Simulation-based reliability assessment", Struct. Eng. Mech., 38(2), 171-193.

Liu, T., Li, A.Q., Ding, Y.L. and Zhao, D.L. (2009), "Study of the structural damage identification method based on multi-mode information fusion", Struct. Eng. Mech., 31(3), 333-347.

Ma, Y.S., Wang, Y.F. and Mao, Z.K. (2011), "Creep effects on dynamic behavior of concrete filled steel tube arch bridge", Struct. Eng. Mech., 37(3), 321-330.

Magura, D.D., Sozen, M.A. and Siess, C.P. (1964), “A study of stress relaxation in prestressing reinforcement”, PCI J, 9(2), 13-53.

McGuire, W., Gallagher, R.H. and Ziemian, R.D. (2002), Matrix structural analysis, John Wiley, New York.

Neville, A.M. (2004), Properties of Concrete, $4^{\text {th }}$ Edition, Prentice Hall, London.

Sapountzakis, E.J. and Katsikadelis, J.T. (2003), "Creep and shrinkage effect on the dynamics of reinforced concrete slab-and-beam structures", J. Sound Vib., 260(3), 403-416.

Zhang, J., Xu, Y.L., Xia, Y. and Li, J. (2008), "A new statistical moment-based structural damage detection method", Struct. Eng. Mech., 30(4), 445-466. 